Article

\title{
Quality Assessment of Biodiesel Blends Proposed by the New Mexican Policy Framework
}

\author{
Marcos A. Coronado ${ }^{1}$, Gisela Montero ${ }^{1, *}$, Conrado García ${ }^{1}$, Benjamín Valdez ${ }^{1}$, Ramón Ayala ${ }^{1}$ \\ and Armando Pérez ${ }^{2}$ \\ 1 Universidad Autónoma de Baja California, Instituto de Ingeniería, Blvd. Benito Juárez, Insurgentes Este, \\ 21280 Mexicali, Mexico; marcos.coronado@uabc.edu.mx (M.A.C.); cnrdgarciag@uabc.edu.mx (C.G.); \\ benval@uabc.edu.mx (B.V.); ramon.ayala@uabc.edu.mx (R.A.) \\ 2 Universidad Autónoma de Baja California, Escuela de Ciencias de la Ingeniería y Tecnología, Unidad Valle \\ de las Palmas, km 10.5 carretera Tijuana, 22260 Tecate, Mexico; armando.perez.sanchez@uabc.edu.mx \\ * Correspondence: gmontero@uabc.edu.mx; Tel.: +52-686-566-4150
}

Academic Editor: Enrico Pontelli

Received: 26 January 2017; Accepted: 27 April 2017; Published: 4 May 2017

\begin{abstract}
Nowadays, biodiesel is being promoted worldwide as a sustainable and alternative to diesel fuel. However, there is still a lack of a biodiesel market in Mexico. Hence, a new initiative to reform the Mexican biofuels framework by decree includes the production and use of biodiesel. This regulation can ensure and contribute to the development of the biodiesel market in Mexico. The initiative proposes to start from the B5.8 blend by the end of 2017 and reach the B10 by 2020 . Therefore, the objective of the present work was the quality assessment of biodiesel blends proposed by the new Mexican policy framework. The techniques applied were Fourier transform infrared (FT-IR) spectroscopy, X-ray fluorescence analysis, scanning electron microscopy analysis, viscosity, higher heating value, thermogravimetric analysis, refractive index, acid number, specific gravity, flash point, and copper strip corrosion based on ASTM standards. The results indicate that the biodiesel and its blends B5.8 and B10 fulfilled relevant quality specifications established in the ASTM D6751 and EN14214 standards for fuels. However, the fuel blends presented a higher heating value (HHV) diminution. The experimental HHV percentages decrease for the mandatory mixtures compared to diesel were $2.29 \%$ (B10), and $0.29 \%$ (B5.8).
\end{abstract}

Keywords: new Mexican policy framework; biodiesel blends; waste vegetable oil; properties; characterization

\section{Introduction}

Currently, climate change, the high oil dependency, energy security issues, low air quality, and health concerns have caused the encouragement and promotion of the production and development of biofuels worldwide [1]. Biofuels are substitutes for fossil fuels obtained from biomass. They can be in the solid, liquid or gaseous state, e.g., biomass pellets and briquettes, biodiesel, bioethanol, biogas, and biohydrogen, among others. Biofuels are classified as first, second, third or fourth generation depending on the raw materials used for their production, e.g., edible raw materials, non-edible raw materials, microalgae, and genetically modified organisms. Biodiesel is one of the most produced biofuels. It is a green and renewable fuel obtained from lipids, vegetable oils and animal fats [2,3]. It is produced by the reaction of triglycerides with a short chain alcohol in the presence of an acid, alkali or enzymatic catalyst to obtain the mixture of fatty acid methyl esters known as biodiesel [4].

Currently, biodiesel is considered a real alternative to diesel fuel due to the following advantages: (a) it can reduce dependence on crude oil imports and enhance energy security; (b) it has a favorable 
energy return on energy invested; (c) it can reduce greenhouse emissions and lower harmful emissions; (d) it is biodegradable, nontoxic, and renewable; and (e) it can help improve rural economies since agricultural wastes are used as the raw material [5].

Biodiesel is typically blended with petroleum diesel at different concentration levels, ranging from $2 \%$ to $20 \%$ [6]. For example, B20 refers to a mixture containing $20 \%$ biodiesel and $80 \%$ diesel. Currently, higher percentages of biodiesel in the fuel mixture are not used or recommended to avoid issues of compatibility with metallic materials and polymers, as well as to ensure the correct operation of the engine, among others [7]. Biodiesel blends higher than B20 require special handling and engine modifications to avoid maintenance and performance problems [8]. For this reason, blends equal or less than B20 are common biodiesel blends in the United States, Europe, and Brazil. Another application of biodiesel that has taken importance is as an oil additive as an improver of lubricating properties, and this also represents a green market option. For its utilization as a fuel biodiesel must comply with different quality requirements that are specified in the ASTM D6751 or EN 14214 standards [9].

The main biodiesel producers globally are the European region and the USA, followed by Argentina, Brazil, Indonesia, Singapore, Thailand, Malaysia, and other countries. The most frequently used feedstocks are rapeseed, soybean, corn, canola, or palm oil, tallow, and white and yellow grease. By 2010, the biodiesel production was 19 billion liters, while in 2013, it was around 25 billion liters. The global biodiesel production grew 47-fold between 2000 and 2013. The rapid global expansion and growth of biodiesel market has been driven by biodiesel mandates enacted worldwide $[10,11]$.

At present, Mexico does not have a biofuel market or a biodiesel industry. However, in 2008, the first Law on the Promotion and Development of Bioenergetics came into force [12]. The objective of this act was to promote the biofuel production derived from agricultural activities, without compromising food safety or sovereignty, as well as reducing pollution and greenhouse effect gas emissions, considering the international instruments contained in the treaties signed by Mexico. Because this law has not had the applicability or the expected results, in 2015, the Law Reform Initiative for the Promotion, Development and Introduction of Renewable Biofuels [13] was presented, with the aim of promoting the creation of the biofuels market. The initiative seeks to promote by decree the mandatory production and use of biofuels throughout the country. The first stated goal is that all gasoline and diesel sold in the country at fuel stations by December 2017 should include at least $5.8 \%(v)$ of bioethanol and biodiesel in the fuel mixture with gasoline and diesel, respectively. It is expected that the biofuel blends will increase to E10 and B10 by December 2020. This regulation can ensure and contribute to the development of the supply chain of biofuels in Mexico, as was achieved in other countries.

Waste vegetable oil (WVO) is one of the most promising feedstocks for biodiesel production in Mexico [14]. It is generated by the food industry, e.g., food processing factories, restaurants, among others. It is a cheap resource and widely available. The main issue is to how ensure its consistent supply. It was estimated that in 2010, Mexico produced between 0.37 and $0.84 \mathrm{Mt}$ of waste vegetable oil [15]. It is a residue that could be valorized for biodiesel production and utilization to reduce the exhaust emissions and to improve the air quality in different cities around the country. With the valorization of WVO in Mexico, it is estimated that it would be feasible to produce some 0.29 to $0.67 \mathrm{Mt}$ of biodiesel. Waste vegetable oil-based biodiesel is a biofuel that can directly substitute for petroleum diesel, and has attracted more attention due to its physicochemical properties which match the requirements for a green environment [16]. This biodiesel can be mixed with diesel at different concentration levels for its utilization in the many applications, e.g., the transport sector, cargo, domestic vehicles, aircraft, ships, and emergency system powers, among others [17].

In 2014, the transportation sector of Mexico accounted for $45.9 \%$ of the final national energy consumption, in which diesel accounted for $26.6 \%$ with 542.28 PJ. This amount is equivalent to a consumption of $15,340,860 \mathrm{~m}^{3}$ of diesel. The utilization of diesel in Mexico mainly occurs in the auto-transport, maritime and rail sectors. The auto-transport sector accounts for $91.3 \%$ of the diesel demand [18]. This sector includes ground transportation services for the movement of people and 
cargo. In 2014, the national diesel base vehicle inventory of the auto-transport sector was made up of 900,000 units, and it is expected to grow in the future [19]. It is the market niche for the B5.8 and B10 biodiesel blends encouraged by the new Law Reform Initiative [13]. Nevertheless, it is necessary to evaluate the properties of these blends to determine if they comply with the quality specs.

Therefore, the objective of the present work was to perform a quality assessment of the properties of these fuel blends. The characterization techniques applied were Fourier transform infrared (FT-IR) spectroscopy, X-ray fluorescence analysis, scanning electron microscopy analysis, viscosity, higher heating value determination, thermogravimetric analysis, refractive index, total acid number determination, specific gravity, flash point determination, and copper strip corrosion based on the ASTM standards.

\section{Materials and Methods}

\subsection{Biodiesel Procurement}

The biodiesel procurement started with the recovery of WVO from a restaurant located on the campus of the Autonomous University of Baja California. Once the WVO was collected, it was filtered to remove solids and then heated at $105^{\circ} \mathrm{C}$ to eliminate the moisture. Afterward, the transesterification reaction was performed at $60^{\circ} \mathrm{C}$ for $1 \mathrm{~h}$ in a suitable reaction vessel in the presence of sodium methoxide and WVO. Due to the fact glycerol is a denser compound than biodiesel, both were separated by gravity in a separation funnel. Then, the biodiesel was washed with the stir washing technique by using a volumetric-water-biodiesel ratio of $4: 1$. Later, the biodiesel was dried at $110{ }^{\circ} \mathrm{C}$ and finally, the biofuel was characterized.

\subsection{Biodiesel Preparation Blends}

In this stage, the following fuel blends were prepared: B2, B5.8, B10, B20, B50, B80, using the biodiesel that was produced and locally obtained ultra-low-sulphur diesel (below $15 \mathrm{ppm}$ ). The fuel blends are depicted in Figure 1.

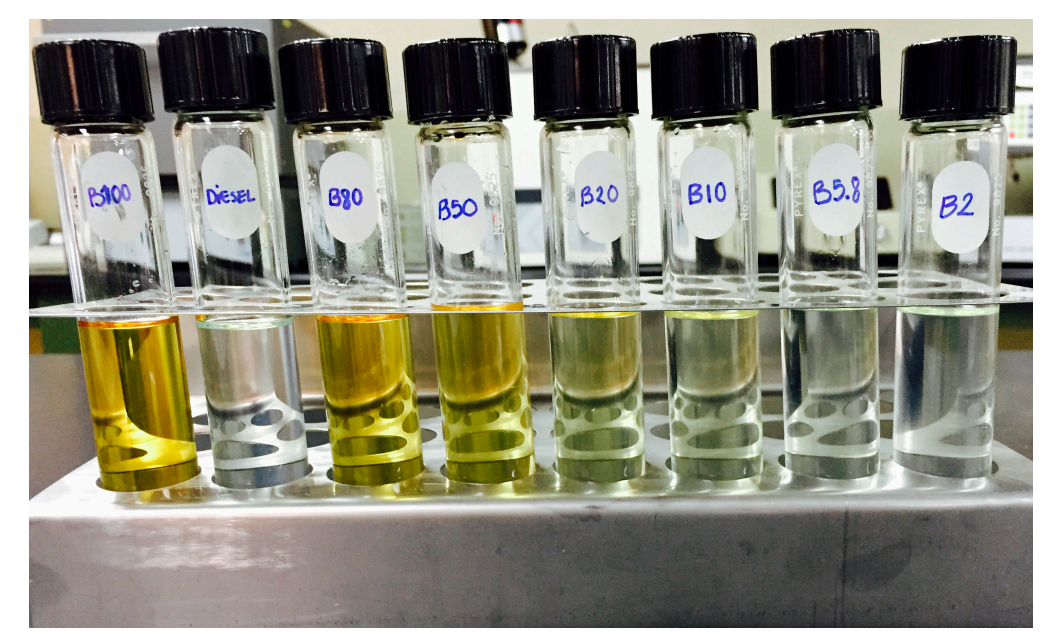

Figure 1. Fuel blends prepared.

\subsection{Analysis by Fourier Transform Infrared Spectroscopy}

The WVO, diesel, and biofuel blends were characterized by FT-IR spectroscopy, using a Spectrum One FT-IR spectrometer (Perkin Elmer, Waltham, MA, USA) with a detector of attenuated total reflection (ATR). The spectra were collected in the range from 400 to $4000 \mathrm{~cm}^{-1}$ with a spectral resolution of $4 \mathrm{~cm}^{-1}$. Sixteen scans were performed for each sample with a medium intensity lamp, and a standard beam setting. 


\subsection{Higher Heating Value Determination}

The higher heating value (HHV) determination was performed for the WVO, diesel, and biodiesel blends in a model C2000 calorimeter (IKA, Staufen, Germany) in duplicate. The operating parameters of the equipment were selected to use the ASTM 711 standard as a basis. The temperature used was $25{ }^{\circ} \mathrm{C}$ with the isoperibolic method.

\subsection{Flash Point Determination}

The flash point was determined for each fuel sample by applying the Standard Test Methods for Flash Point by a Pensky-Martens Closed Cup Tester as specified in the ASTM D93 norm.

\subsection{Standard Test Method for Corrosiveness to Copper from Petroleum Products by Copper Strip Test}

The ASTM D130 test (Test Method for Corrosiveness to Copper from Petroleum Products by Copper Strip Test) is applied to assess the relative degree of corrosivity of a petroleum product. Although biodiesel is not a petroleum-based fuel, this is the official standard applied worldwide. It consists in the immersion of a freshly polished copper strip in a defined volume of the fuel being tested (in the current study diesel and biodiesel blends) and heated under conditions of temperature and time that are determined to the class of material being tested. At the end of the heating period, the copper strip is removed, washed and the color and tarnish level is assessed against the ASTM Copper Strip Corrosion Standard that is shown in Figure 2.

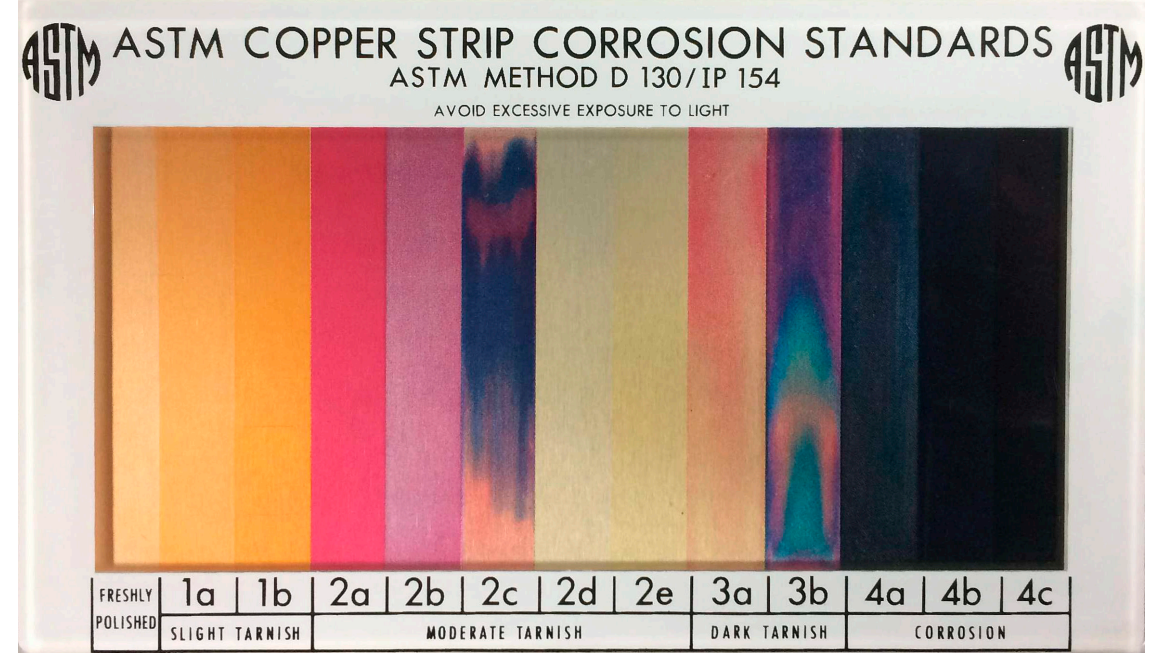

Figure 2. ASTM copper strip corrosion standard.

In the present work, certified copper of $99.95 \%$ of purity was acquired. Samples of $12.5 \mathrm{~mm} \times 75 \mathrm{~mm}$ were cut. They were polished with grade $600 \mathrm{SiC}$ sheets (Fandeli, Mexico City, Mexico). Then, the copper samples were rinsed with water and degreased with acetone and once dried, they were drilled. The copper corrosion test was performed following the experimental conditions established in the ASTM D130 assay.

\subsection{Scanning Electron Microcopy and Energy-Dispersive X-ray Spectroscopy Analysis}

After the ASTM D130 was applied, the copper strips exposed to the different fuel samples were analyzed through the scanning electron microscopy (SEM) analysis technique. It was achieved with a JSM-6010LA scanning electron microscope (JEOL, Akishima, Tokyo, Japan). The instrument consists of an energy-dispersive X-ray spectroscopy (EDS) analyzer and a retrodispersed electron detector to capture images. It was operated under conditions of low vacuum and an accelerating voltage between $15 \mathrm{kV}$ and $20 \mathrm{kV}$. The magnification of the images was $500 \times$. 


\subsection{Acid Number Determination}

The acid number determination was based on ASTM D664. It was determined before and after the corrosion strip test. This parameter is significant because it reveals the fuel quality and its degradation.

\subsection{Refractometry Analysis}

The refractive index of each fuel was determined in an A. KRÜSS OPTRONIC AR 2008 refractometer (KRÜSS, Hamburg, Germany) at $25^{\circ} \mathrm{C}$.

\subsection{Specific Gravity Measurement}

The specific gravity of each fuel sample was determined by gravity hydrometers for light liquids at $15{ }^{\circ} \mathrm{C}$.

\subsection{Viscosity}

The dynamic viscosity profile of all fuel samples was measured with a CAP 2000+ viscometer (Brookfield, Middleboro, MA, USA) from $50{ }^{\circ} \mathrm{C}$ to $91^{\circ} \mathrm{C}$.

\subsection{Thermogravimetric (TG) Analysis}

The TG analysis was carried out in a Perkin-Elmer STA 6000 Simultaneous Thermal Analyzer (Perkin Elmer, Waltham, MA, USA). The sample size for each type of fuel was $5 \mathrm{mg}$. The analysis method was described as follows. The initial temperature was $30^{\circ} \mathrm{C}$, using $\mathrm{N}_{2}$ as the carrier gas, with a flow rate of $20 \mathrm{~cm}^{3} / \mathrm{min}$. Four temperature increase ranges were executed. The first range was from $30{ }^{\circ} \mathrm{C}$ to $120^{\circ} \mathrm{C}$, with increments of $10^{\circ} \mathrm{C} / \mathrm{min}$. The second range was from $120^{\circ} \mathrm{C}$ to $360{ }^{\circ} \mathrm{C}$, with increases of $10^{\circ} \mathrm{C} / \mathrm{min}$. The third stage was from $360^{\circ} \mathrm{C}$ to $850{ }^{\circ} \mathrm{C}$ with increases of $20^{\circ} \mathrm{C} / \mathrm{min}$. Finally, the last phase served to cool the equipment, lowering the temperature from $850{ }^{\circ} \mathrm{C}$ to $30^{\circ} \mathrm{C}$ with decrements of $50{ }^{\circ} \mathrm{C} / \mathrm{min}$.

\subsection{X-ray Fluorescence Spectrometer Analysis}

The fuel samples were analyzed by the X-ray fluorescence (XRF) spectrometer of dispersed energy, using a EDX-7000 instrument (Shimadzu, Kyoto, Japan). The X-ray generator consists of a tube that uses the rhodium (Rh) element as a target, and it was set at $50 \mathrm{kV}$ and $283 \mu \mathrm{A}$. The operation characteristics allowed determining the majority of elements found in the samples, in a range that covers from sodium to uranium. The $\mathrm{X}$-ray fluorescence lines emitted by the samples were identified using a silicon drift detector (SDD) (Shimadzu, Kyoto, Japan).

\section{Results}

\subsection{FT-IR Analyses Results}

Figure 3 presents the spectra of the infrared absorption corresponding to biodiesel obtained from waste vegetable oil and its different blends with diesel. The spectrum with the highest intensity peaks corresponds to B100, followed by spectra of B80, B50, B20, B10, B5.8 and B2.

In the biodiesel spectra as well as in their different mixtures, absorption bands characteristic of fatty acid esters are observed. Two strong absorptions are observed at 2924 and $2854 \mathrm{~cm}^{-1}$ corresponding to the asymmetric and symmetrical stretches of the $\mathrm{CH}_{3}, \mathrm{CH}_{2}$ and $\mathrm{CH}$ groups, typical of the aliphatic carbons. Another characteristic absorption band of biodiesel is observed at $1742 \mathrm{~cm}^{-1}$, this high absorption is attributed to the stretching of the $\mathrm{C}=\mathrm{O}$ double bond of the carbonyl group. Also, three well-defined peaks at 1457, 1435, and $1359 \mathrm{~cm}^{-1}$ are identified and attributed to the flexion or deformation experienced by the $\mathrm{C}-\mathrm{H}$ bond. 


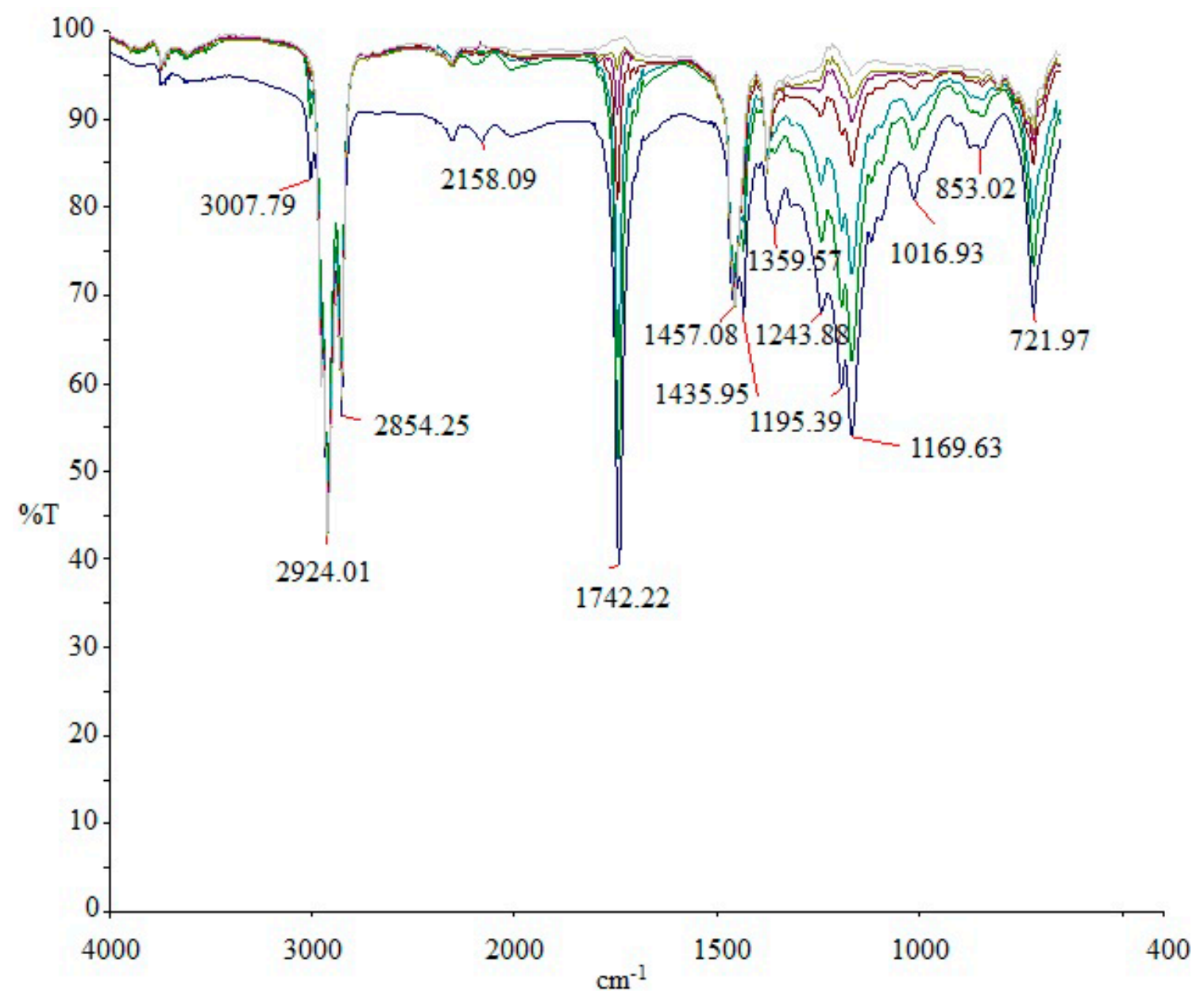

Figure 3. Fourier transform infrared (FT-IR) spectra of biodiesel blends.

A group of absorption bands typical of the methyl esters that make up the biodiesel is observed in the fingerprint region (1400 and $\left.600 \mathrm{~cm}^{-1}\right)$. These bands are originated by the asymmetric axial deformation of the $\mathrm{C}-\mathrm{O}$ bond. A more detailed description of the peaks observed in this region is shown in Table $1[20,21]$.

Table 1. Fourier transform infrared (FT-IR) peaks description.

\begin{tabular}{cc}
\hline Wavenumber $\left(\mathbf{c m}^{-\mathbf{1}}\right)$ & Type of Vibration \\
\hline 2924 & Asymmetric stretch of $\mathrm{CH}, \mathrm{CH}_{2}, \mathrm{CH}_{3}$ \\
2854 & Symmetric stretch of $\mathrm{CH}, \mathrm{CH}_{2}, \mathrm{CH}_{3}$ \\
1742 & Stretch of the carbonyl group bond $\mathrm{C}=\mathrm{O}$ \\
1457 and 1435 & Asymmetric deformation of the bonds $\mathrm{CH}, \mathrm{CH}_{2}, \mathrm{CH}_{3}$ \\
1243 & Deformation of the bond $\mathrm{C}-\mathrm{O}$ \\
1195 & Axial deformation of the ester bond $\mathrm{CC}(=\mathrm{O})-\mathrm{O}$ \\
1195 & Axial asymmetric deformation of the bond $\mathrm{O}-\mathrm{C}-\mathrm{C}$ \\
\hline
\end{tabular}

With the spectra shown in Figures 3 and 4, it is possible to highlight and identify the main structural differences between diesel and biodiesel. In the diesel and biodiesel spectra, absorption bands of the stretches and deformations of the $\mathrm{C}-\mathrm{H}$ bonds are observed. 


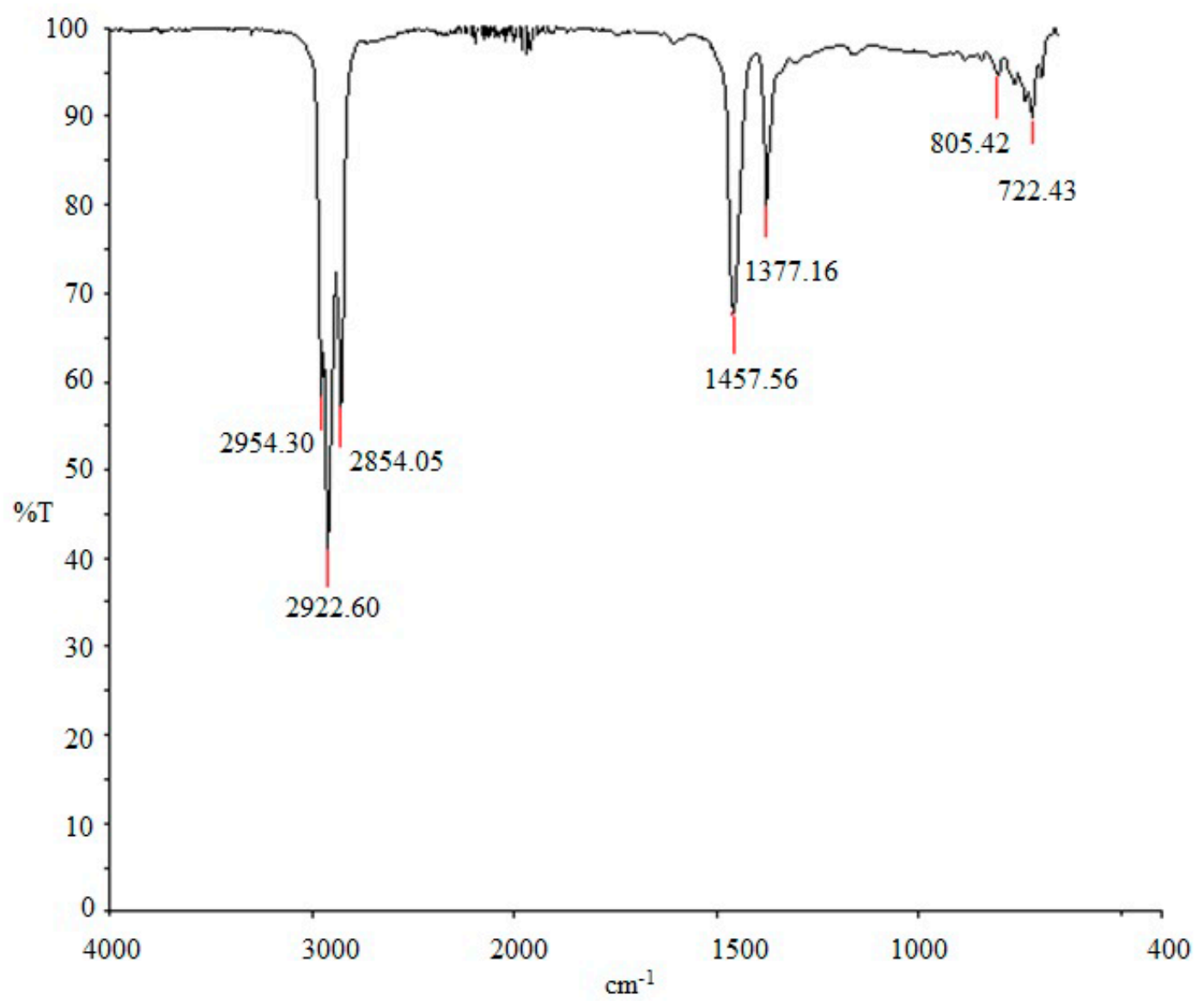

Figure 4. FT-IR spectrum of diesel.

However, the infrared spectrum of the diesel does not have carbonyl groups, and no absorption is presented in the fingerprint region, indicating an absence of $\mathrm{C}-\mathrm{O}$ bonds. This explains the decrease of the peak intensity around $1740 \mathrm{~cm}^{-1}$ as the concentration of diesel in the mixture increases. Therefore, the peak intensity generated by the carbonyl group can be used for the determination of the concentration of biodiesel in these mixtures.

\subsection{Higher Heating Value and Flash Point Results}

The HHV of diesel was $45.02 \mathrm{MJ} / \mathrm{kg}$ and, the HHV of biodiesel blends varied from $44.89 \mathrm{MJ} / \mathrm{kg}$ for $\mathrm{B} 2$ to $39.06 \mathrm{MJ} / \mathrm{kg}$ for B100. The HHV of B100 was $13.26 \%$ less than the HHV of diesel. The percentages decrease of the HHV for the remaining diesel-biodiesel mixtures compared to diesel were $11.31 \%$ (B80), $7.58 \%$ (B50), 3.90\% (B20), 2.29\% (B10), and 0.29\% (B5.8). Figure 5 depicts a decreasing trend of HHV as the biodiesel concentration increases in the fuel blend. The decrease of the HHV of both biodiesel and its blends represents a significant disadvantage compared to diesel since it implies direct repercussions that would be reflected in a reduction of power and torque of the engine, as well as an increase in the consumption of fuel [22,23].

The flash point of diesel was $59^{\circ} \mathrm{C}$. Among the fuel samples, the highest flash point was $178{ }^{\circ} \mathrm{C}$ for B100, and the lowest was $60^{\circ} \mathrm{C}$ for B2. The ASTM D6751 standard establishes that the flash point of B100 must be above $93^{\circ} \mathrm{C}$. Therefore, the B100 from WVO complied with the specification. Figure 5 reflects a direct correlation between biodiesel concentration and the flash point, and an inverse correlation between biodiesel concentration and HHV. 


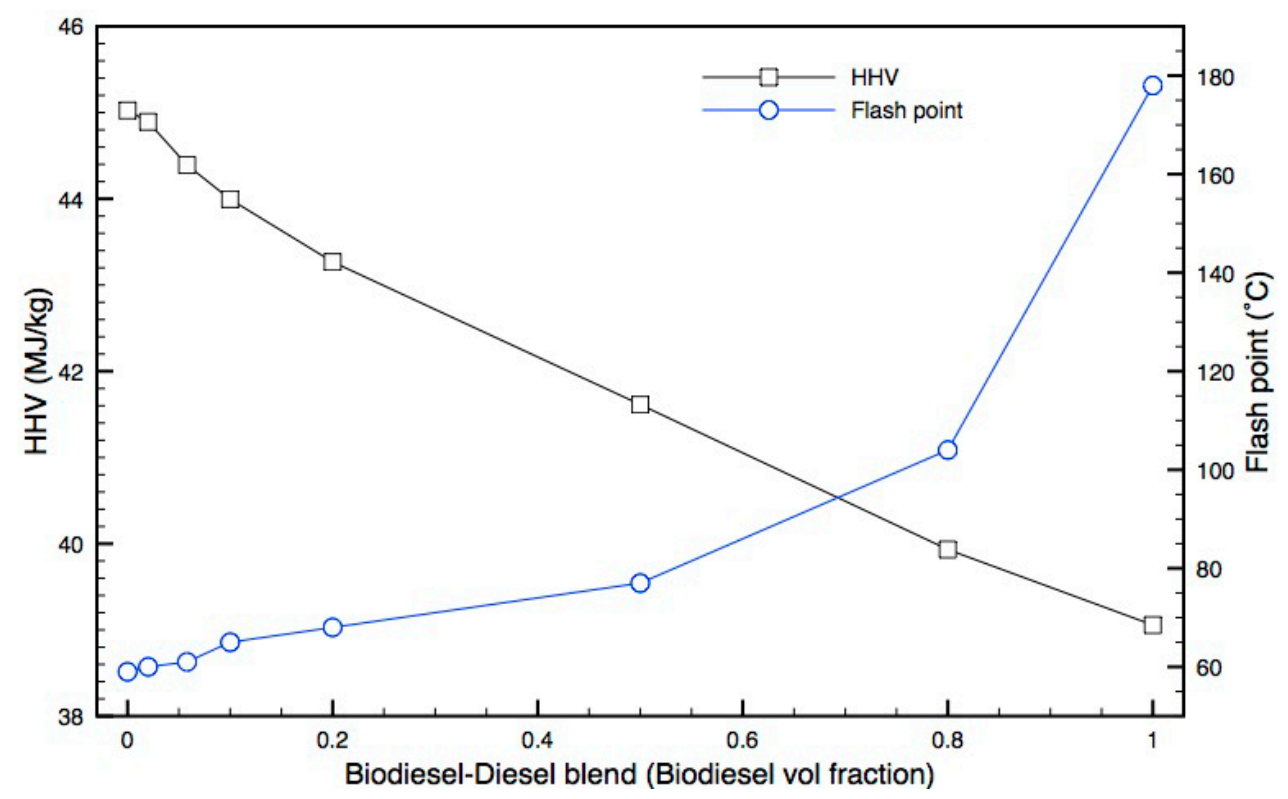

Figure 5. Higher heating value (HHV) and flash point of biodiesel blends.

\subsection{Standard Test Method for Corrosiveness to Copper from Petroleum Products by Copper Strip Test}

The copper strips exposed to all the tested fuels presented a slight tarnish in some localized zones. The highest intensity was observed in those samples exposed to the fuel blends with the greater biodiesel concentration. However, the classification for all the copper strips was 1a, a value that is within limits specified in the ASTM D130. Figure 6 illustrates the copper strips exposed to the fuel blends compared with the blank.

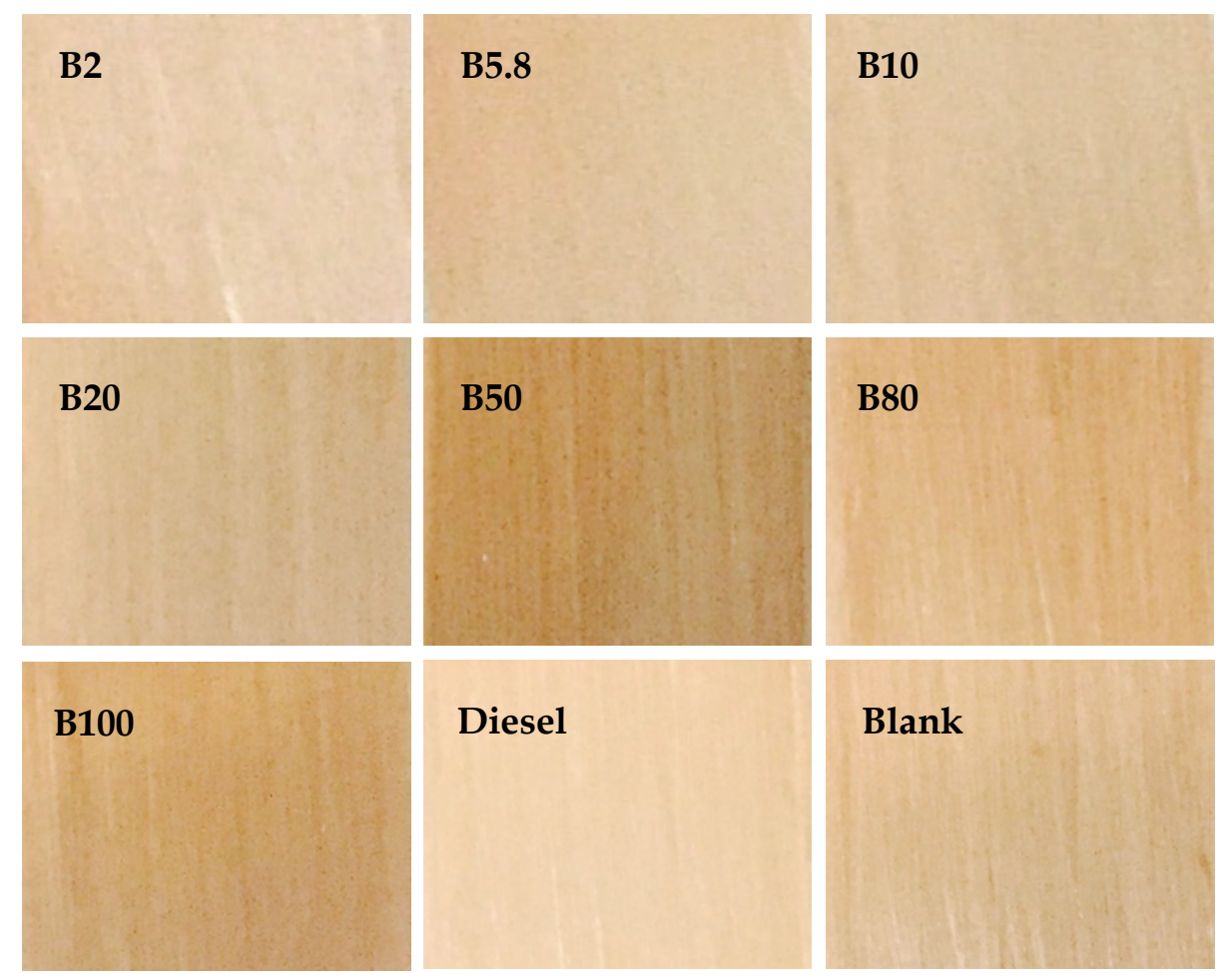

Figure 6. Copper strips after the corrosion test according to ASTM D130. 


\subsection{SEM Results}

Micrographs of the copper strips exposed to the different fuels are presented in Figure 7. The surface morphology analysis through SEM, evidence that there are no significant changes in the copper strips after the ASTM D130 test.
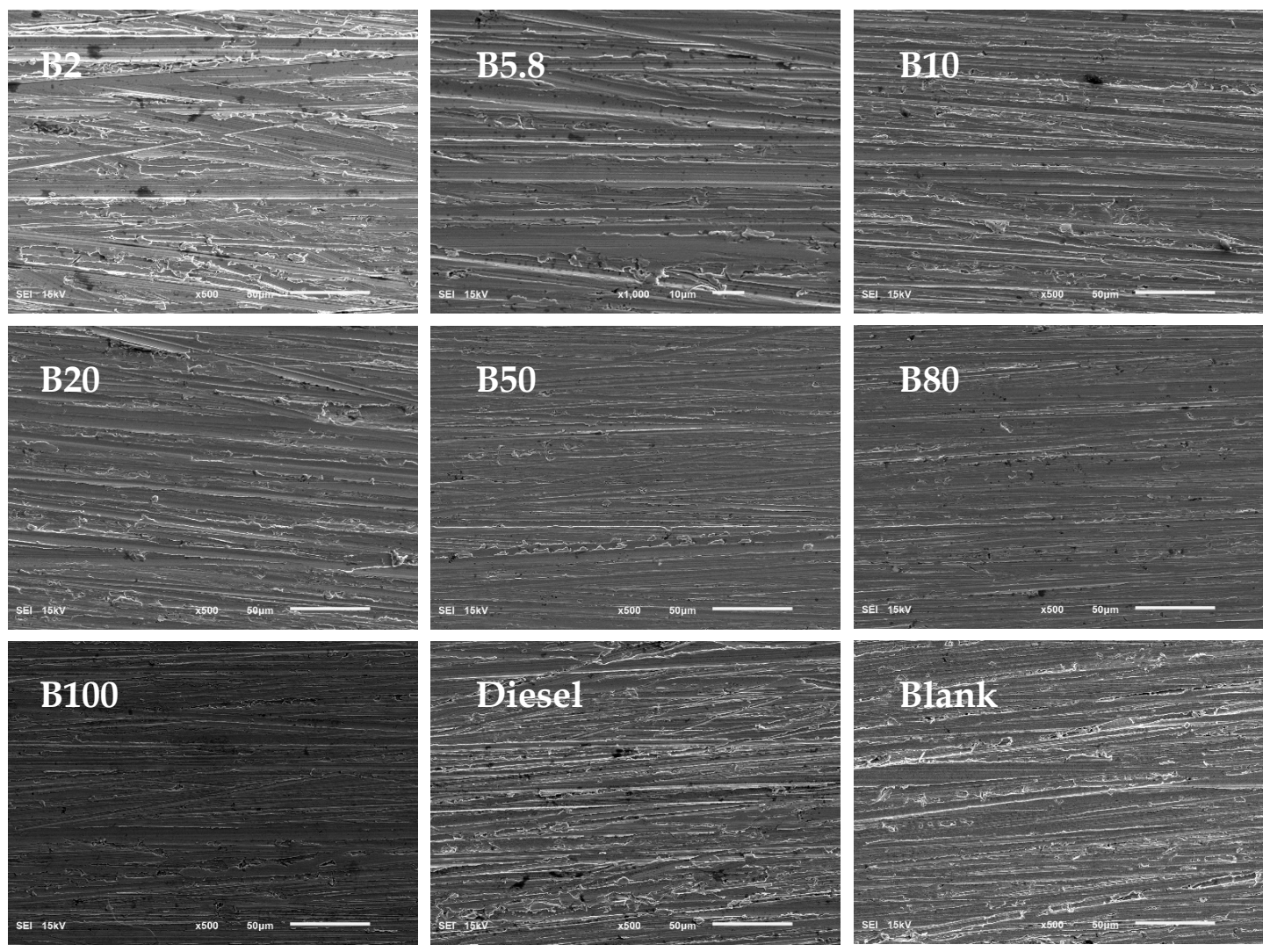

Figure 7. Scanning electron microscopy (SEM) images of copper strips at $500 \times$.

The SEM results and the copper strip corrosion test did not reflect significant corrosive effects of the different fuels. The ASTM D130 is dedicated to evaluate the corrosivity of copper to sulphur compounds remaining in the petroleum product. However, the biodiesel has a very low or zero content of sulphur compounds and the diesel used in the current work was ultra-low-sulphur level, below $15 \mathrm{ppm}$. Hence, the biodiesel, diesel and fuel blends comply with this standard.

\subsection{Acid Number Determination Results}

Figure 8 illustrates the acid number change for each fuel used in the corrosion strip test. The B100 experienced the most significant change in acidity compared to diesel, followed by the others diesel-biodiesel blends. The diesel acid number remained almost constant. The results are consistent with the data reported in the scientific literature that reflects the biodiesel degradation tendency.

The acid number is a parameter directly related to the content of free fatty acids. It is considered as a measure of the corrosivity and the degradation effect of biodiesel. This parameter increases as a result of fuel oxidation. Acidic conditions exceeding the standard ASTM 6751 specifications provoke further swelling and degradation in elastomers, and corrosion issues in metallic materials [7]. In this case, the B100, B80, and B50 are out of spec fuels. 


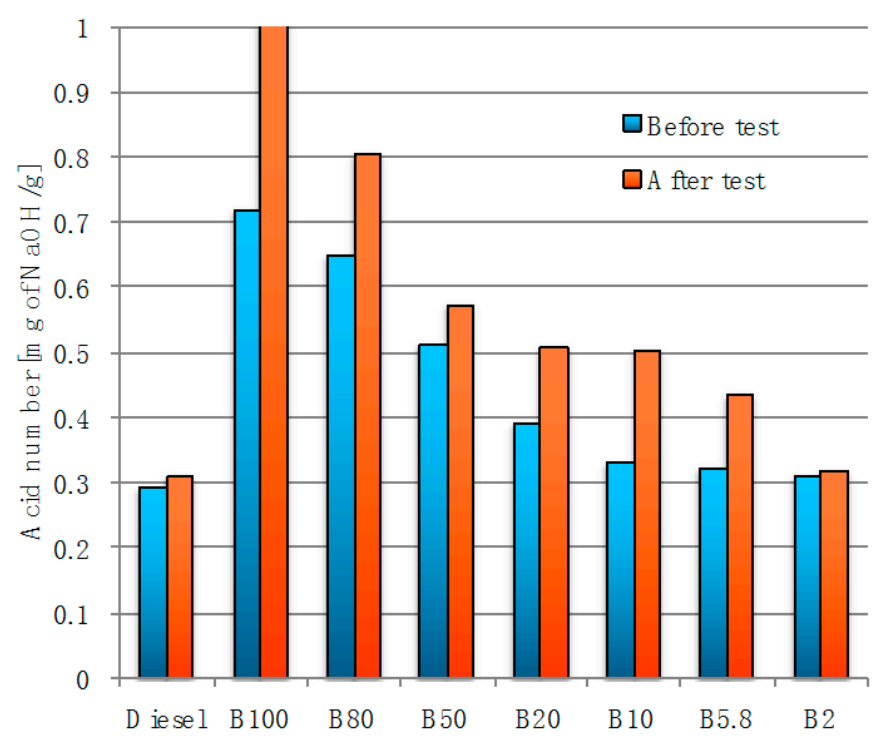

Figure 8. Acid number of fuels before and after the test.

\subsection{Refractive Index and Specific Gravity Results}

The measured refractive index of diesel was 1.4642 whereas for biodiesel was 1.4598 . The values of the remnant blends were between the values obtained for the diesel and biodiesel. In Figure 9 can be seen that as biodiesel concentration increased in the fuel blend, the refractive index decreased. The values are found within the rank reported in the literature [24,25]. The specific gravity increased linearly as the biodiesel concentration augmented in the fuel blend. The specific gravity for diesel was 0.838 and for B100 was 0.888 . The specific gravity measured for each fuel was within the values reported by the EN 12214 regulations and other authors [25].

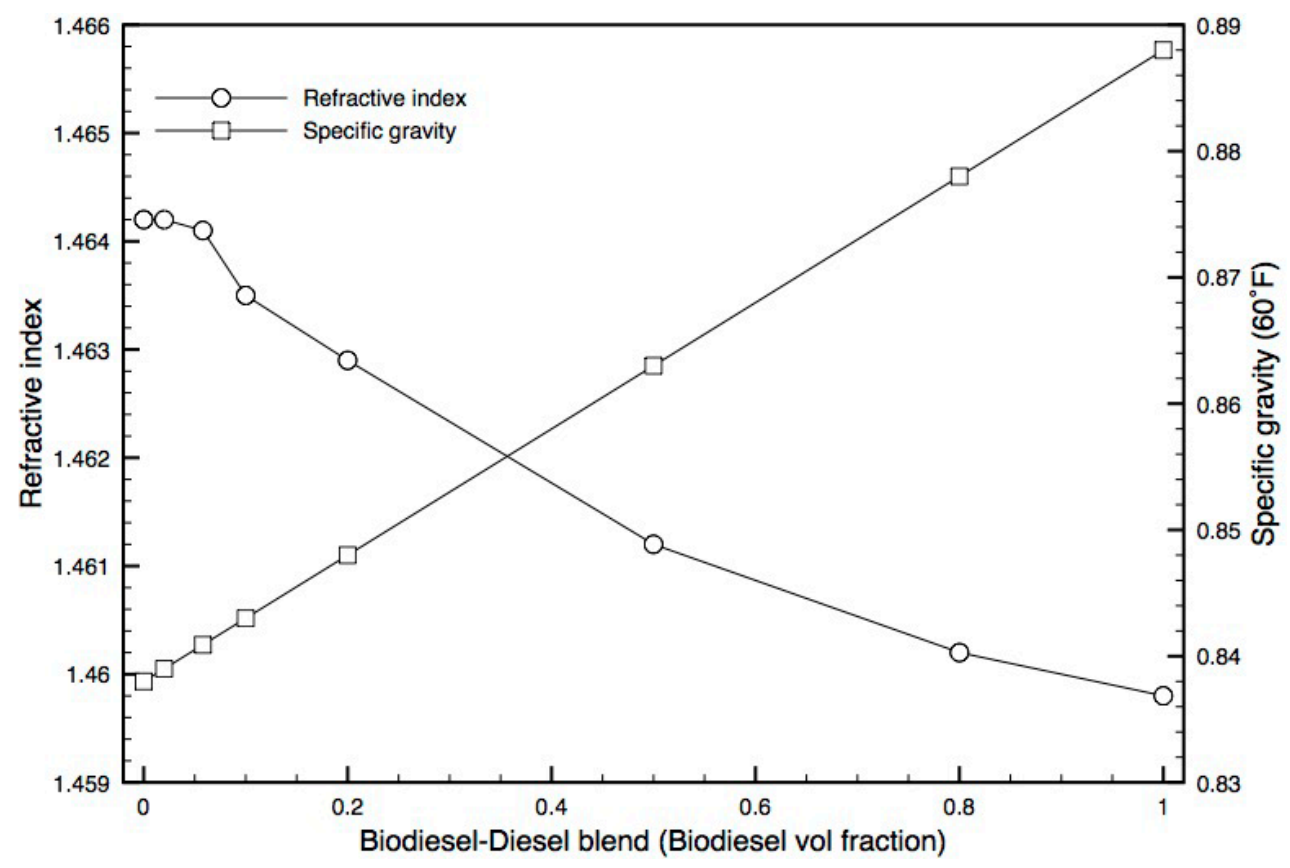

Figure 9. Refractive index and specific gravity of the fuel samples. 


\subsection{Viscosity Results}

Figure 10 describes the viscosity profile for each fuel from $50{ }^{\circ} \mathrm{C}$ to $91^{\circ} \mathrm{C}$. The viscosity increased as the biodiesel concentration augmented. It is highlighted that the viscosity diminished as the temperature raised. The B100 is in-spec according to the ASTM D6751 and the EN14214.

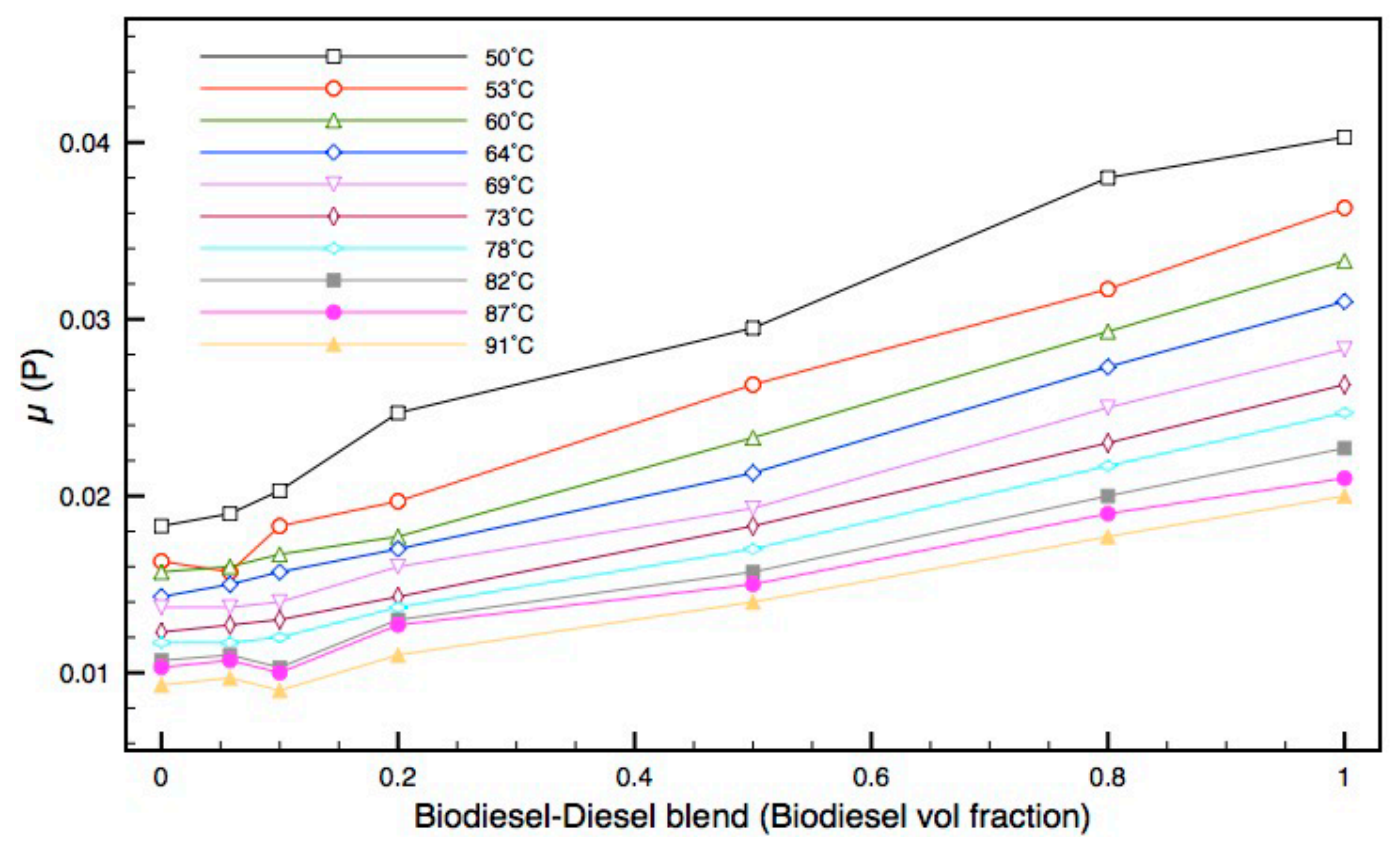

Figure 10. Viscosity profile of each fuel.

\subsection{Thermogravimetric Analysis Results}

In Figure 11, the thermogravimetric (TG) curves for each type of fuel tested are presented. The biodiesel experienced the highest mass loss of $82.96 \%$ between $100{ }^{\circ} \mathrm{C}$ and $250{ }^{\circ} \mathrm{C}$ and $15.89 \%$ between $250{ }^{\circ} \mathrm{C}$ and $500{ }^{\circ} \mathrm{C}$. It was attributed to the decomposition and/or volatilization of methyl esters. The diesel had the highest mass loss of $84.63 \%$ between $100^{\circ} \mathrm{C}$ and $250{ }^{\circ} \mathrm{C}$. The results of the TG curves show that as the biodiesel concentration increases in the fuel blend, the thermal stability rises as well.

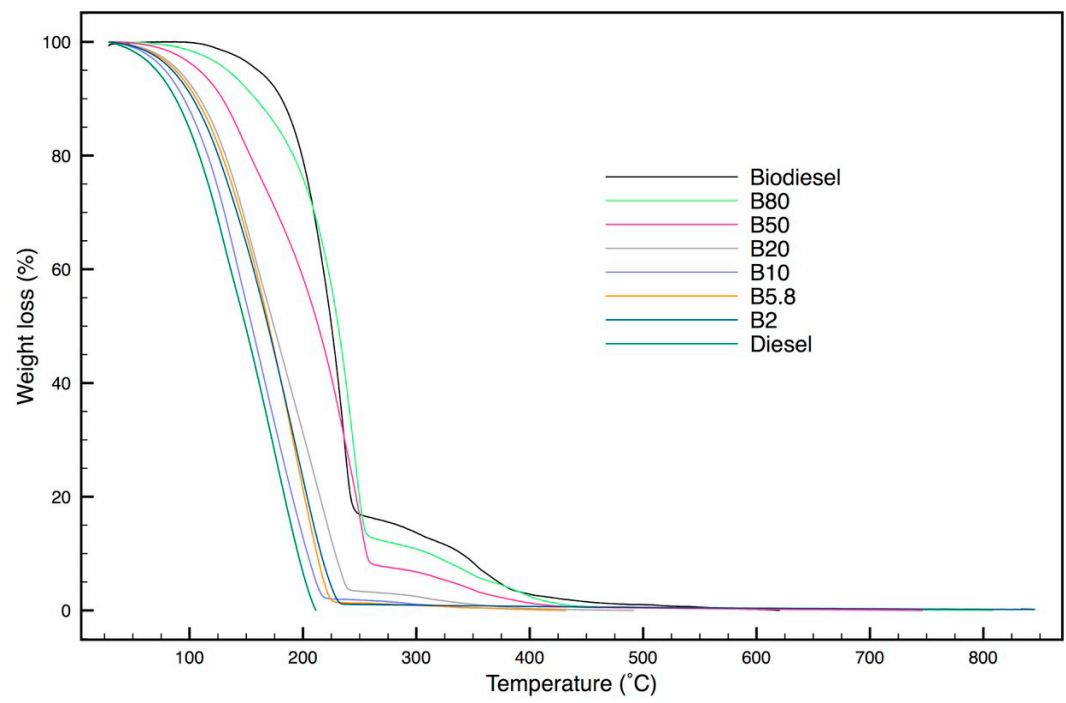

Figure 11. Thermogravimetric (TG) curves of the tested fuels. 


\subsection{X-ray Fluorescence Spectrometer Analysis Results}

The XRF analysis highlighted the presence of sulphur in the diesel, as can be seen in Table 2 . Regarding the biodiesel and the diesel-biodiesel blends the presence of copper was detected. It suggests a corrosive effect of these fuels on copper strips.

Table 2. X-ray fluorescence (XRF) results of the fuels.

\begin{tabular}{cccccc}
\hline \multirow{2}{*}{ Fuel } & \multicolumn{5}{c}{ Analyte (\%) } \\
\cline { 2 - 6 } & Si & S & Cu & Ca & K \\
\hline Diesel & 59.944 & 40.056 & - & - & - \\
B100 & 90.016 & - & 9.984 & - & - \\
B80 & 88.736 & - & 11.264 & - & - \\
B50 & 86.061 & - & 13.939 & - & - \\
B20 & 100 & - & - & - & - \\
B10 & - & - & 17.434 & 42.120 & 40.446 \\
B5.8 & 100 & - & - & - & - \\
B2 & 100 & - & - & - & - \\
\hline
\end{tabular}

\section{Conclusions}

The production of second-generation biodiesel from waste vegetable oil and the determination of properties and characterization of different diesel-biodiesel blends (B0, B2, B5.8, B10, B20, B50, B80, B100) through the application of FT-IR spectroscopy, X-ray fluorescence analysis, SEM analysis, viscosity, higher heating value determination, thermogravimetric analysis, refractive index, total acid number determination, specific gravity, flash point determination, and copper strip corrosion based on the ASTM standards were performed. Biodiesel and its blends with diesel met the relevant specifications established in the ASTM D6751 and EN14214 fuel standards.

In addition to the results obtained in the quality assessment of these fuel blends, it is necessary to carry out field tests considering a representative statistical sample of the diesel vehicle fleet of the auto-transport sector of Mexico, comprised by 900,000 vehicles. To meet the demand of this auto-transport sector $862,339.20 \mathrm{~m}^{3}$ of biodiesel are required for the B5.8 blend. For the B10 blend, a volume of $1,486,791.70 \mathrm{~m}^{3}$ of biodiesel is needed.

The production of biodiesel from waste vegetable oil represents a real opportunity for the fuel market of Mexico to partially replace part of the national demand for petroleum diesel. It is an ecofriendly and sustainable alternative that allows the valorization and conversion of a biomass residue, in this case WVO, into a biofuel. With the biodiesel from waste vegetable oil, it would be possible to cover $62.68 \%$ and $36.35 \%$ of the demand for B5.8 and B10 blends, respectively. Therefore, it is necessary to consider other raw materials that do not compete with food to meet the full required national demand. The utilization of low biodiesel blends as B5.8 and B10, proposed in the new Mexican reform initiative to the Law of Promotion and Development of Bioenergetics is a feasible option because their properties and characteristics are in spec and similar to those of diesel.

Acknowledgments: The authors thank the National Council on Science and Technology (CONACYT) and the Engineering Institute of the Autonomous University of Baja California for its support in the development of this work.

Author Contributions: Marcos A. Coronado and Gisela Montero conceived the structure of the whole manuscript and contributed to its preparation and writing; Conrado García and Benjamín Valdez performed the experiments and analyzed the results; Ramón Ayala and Armando Pérez prepared the graphic materials.

Conflicts of Interest: The authors declare no conflict of interest. 


\section{References}

1. Ganjehkaviri, A.; Mohd Jaafar, M.N.; Hosseini, S.E.; Musthafa, A.B. Performance Evaluation of Palm Oil-Based Biodiesel Combustion in an Oil Burner. Energies 2016, 9, 97. [CrossRef]

2. Pérez, A.; Ramos, R.; Montero, G.; Coronado, M.; García, C.; Pérez, R. Virtual Instrument for Emissions Measurement of Internal Combustion Engines. J. Anal. Methods Chem. 2016, 2016, 1-13. [CrossRef] [PubMed]

3. León, J.A.; Montero, G.; Coronado, M.; Ayala, J.R.; García, C.; Luna, A.; Vázquez, A. Solar Energy for a Solvent Recovery Stage in a Biodiesel Production Process. Int. J. Photoenergy 2016, 2016, 1-7. [CrossRef]

4. Montero, G.; Stoytcheva, M.; Coronado, M.; García, C.; Cerezo, J.; Toscano, L.; Vázquez, A.; León, J.A. An overview of biodiesel production in Mexico. In Biofuels—Status and Perspective; Biernat, K., Ed.; InTech: Rijeka, Croatia, 2015; pp. 413-424.

5. Fan, X.; Burton, R. Recent development of biodiesel feedstocks and the applications of glycerol: A review. Open Fuels Energy Sci. J. 2009, 2, 100-109. [CrossRef]

6. Rizalman, O.M.; Faizal, C.K. Review of the effects of additives on biodiesel properties, performance, and emission features. J. Renew. Sustain. Energy 2013, 5, 1-15.

7. Coronado, M.; Montero, G.; Valdez, B.; Stoytcheva, M.; Eliezer, A.; García, C.; Campbell, H.; Pérez, A. Degradation of nitrile rubber fuel hose by biodiesel use. Energy 2014, 68, 364-369. [CrossRef]

8. United States Environmental Protection Agency (EPA). Biodiesel, Technical Highlights. 2010. Available online: nepis.epa.gov/Exe/ZyPURL.cgi?Dockey=P1006V0I.TXT (accessed on 5 December 2016).

9. Coronado, M.; Montero, G.; Eliezer, A.; García, C.; Cerezo, J.; Pérez, L.; Ayala, J.R. Materials technological challenges for the biodiesel industry development in Mexico. In Materials and Processes for Energy: Communicating Current Research and Technological Developments; Méndez-Vilas, A., Ed.; Formatex Research Center: Badajoz, Spain, 2013; pp. 279-288.

10. International Renewable Energy Agency (IRENA). Global Bioenergy Supply and Demand Projections. 2014. Available online: http://irena.org/remap/IRENA_REmap_2030_Biomass_paper_2014.pdf (accessed on 7 December 2016).

11. Lee, H.V.; Juan, J.C.; Taufiq-Yap, Y.H.; Kong, P.S.; Rahman, N.A. Advancement in heterogeneous base catalyzed technology: An efficient production of biodiesel fuels. J. Renew. Sustain. Energy 2015, 7, 1-46. [CrossRef]

12. Diario Oficial de la Federación (DOF). Ley de Promoción y Desarrollo de los Bioenergéticos. 2008. Available online: http://www.diputados.gob.mx/LeyesBiblio/pdf/LPDB.pdf (accessed on 5 December 2016). (In Spanish)

13. Gaceta Parlamentaria. Iniciativa que reforma y adiciona diversas disposiciones de la Ley de Promoción y Desarrollo de los Bioenergéticos. Gaceta Parlamentaria año XVIII, No. 4176-X. 2014. Available online: http:/ /gaceta.diputados.gob.mx/Gaceta/62/2014/dic/20141215-X.html\#Iniciativa4 (accessed on 12 December 2016). (In Spanish)

14. Chhetri, A.B.; Watts, K.C.; Islam, M.R. Waste Cooking Oil as an Alternate Feedstock for Biodiesel Production. Energies 2008, 1, 3-18. [CrossRef]

15. Sheinbaum, C.; Calderón, A.; Ramírez, M. Potential of biodiesel from waste cooking oil in Mexico. Biomass Bioenergy 2013, 56, 230-238. [CrossRef]

16. Alhassan, F.H.; Rashid, U.; Taufiq-Yap, Y. Optimization of simultaneous production of waste cooking oil based-biodiesel using iron-manganese doped zirconia-supported molybdenum oxide nanoparticles catalyst. J. Renew. Sustain. Energy 2016, 8, 1-13. [CrossRef]

17. Elkady, M.F.; Zaatout, A.; Balbaa, O. Production of Biodiesel from Waste Vegetable Oil via KM Micromixer. J. Chem. 2015, 2015, 1-9. [CrossRef]

18. Secretariat of Energy (SENER). National Energy Balance. 2014. Available online: https://www.gob.mx/cms / uploads/attachment/file/44353/Balance_Nacional_de_Energ_a_2014.pdf (accessed on 13 December 2016). (In Spanish)

19. Secretariat of Energy (SENER). Prospective of Crude Oil and Petroleum Products 2015-2029, 2015. Available online: https://www.gob.mx/cms/uploads/attachment/file/44327/Prospectiva_Petroleo_ Crudo_y_Petroliferos.pdf (accessed on 15 December 2016). (In Spanish)

20. Pimentel, M.F.; Ribeiro, G.M.; Da Cruz, R.S.; Stragevitch, L.; Pacheco, J.; Teixeira, L. Determination of biodiesel content when blended with mineral diesel fuel using infrared spectroscopy and multivariate calibration. Microchem. J. 2006, 82, 201-206. [CrossRef] 
21. De Lira, L.; De Vasconcelos, F.; Pereira, C.F.; Silveira, A.; Stragevitch, L.; Pimentel, M. Prediction of properties of diesel/biodiesel blends by infrared spectroscopy and multivariate calibration. Fuel 2010, 89, 405-409. [CrossRef]

22. Benavides, A.; Benjumea, P.; Pashova, V. El biodiesel de aceite de higuerilla como combustible alternativo para motores Diesel. Dyna 2007, 74, 141-150. (In Spanish).

23. Mattarelli, E.; Rinaldini, C.A.; Savioli, T. Combustion Analysis of a Diesel Engine Running on Different Biodiesel Blends. Energies 2015, 8, 3047-3057. [CrossRef]

24. Nita, I.; Geacai, S.; Neagu, A.; Geacai, E. Estimation of the refractive index of diesel fuel biodiesel blends. Ovidius Univ. Ann. Chem. 2013, 24, 24-26. [CrossRef]

25. Nita, I.; Geacai, S.; Iulian, O. Measurements and correlations of physico-chemical properties to composition of pseudo-binary mixtures with biodiesel. Renew. Energy 2011, 36, 3417-3423. [CrossRef]

(C) 2017 by the authors. Licensee MDPI, Basel, Switzerland. This article is an open access article distributed under the terms and conditions of the Creative Commons Attribution (CC BY) license (http:/ / creativecommons.org/licenses/by/4.0/). 